\title{
Explicit solution for non-classical one-phase Stefan problem with variable thermal coefficients and two different heat source terms
}

\author{
Julieta Bollati ${ }^{1}$, Maria Natale ${ }^{2}$, Jose A. Semitiel ${ }^{2}$, and Domingo Tarzia ${ }^{1}$ \\ ${ }^{1}$ Univ. Austral and CONICET \\ ${ }^{2}$ Universidad Austral Buenos Aires - Sede Rosario
}

January 27, 2022

\begin{abstract}
A one-phase Stefan problem for a semi-infinite material is studied for special functional forms of the thermal conductivity and specific heat depending on the temperature of the phase-change material. Using the similarity transformation technique, an explicit solution for these situations are shown. The mathematical analysis is made for two different kinds of heat source terms, and the existence and uniqueness of the solutions are proved.
\end{abstract}

\section{Hosted file}

BoNaSeTa-SubmittedToMathMethApplSci-11-01-2022.pdf available at https://authorea.com/users/ 457540/articles/554292-explicit-solution-for-non-classical-one-phase-stefan-problemwith-variable-thermal-coefficients-and-two-different-heat-source-terms 